\title{
Ascending thoracic aortic aneurysm: Usefulness of the speckle-tracking transesophageal echocardiogram
}

\author{
Cipriano Abad, MD, PhD, EBGS, EBCTS
}

\footnotetext{
From the Cardiovascular Surgery Department, University Hospital of Gran Canaria Doctor Negrin, Las Palmas de Gran Canaria, Spain.

Disclosures: Author has nothing to disclose with regard to commercial support.

Received for publication Nov 15, 2016; accepted for publication Nov 17, 2016; available ahead of print Jan 5 , 2017.

Address for reprints: Cipriano Abad, MD, PhD, EBGS, EBCTS, Cardiovascular Surgery Department, University Hospital de Gran Canaria Doctor Negrin, Barranco de La Ballena sn, Las Palmas de Gran Canaria 35010, Spain (E-mail: cprnabad2@gmail.com).

J Thorac Cardiovasc Surg 2017;153:789-90

$0022-5223 / \$ 36.00$

Copyright (c) 2016 by The American Association for Thoracic Surgery

http://dx.doi.org/10.1016/j.jtcvs.2016.11.050
}

In this issue of the Journal, Alreshidan and colleages ${ }^{1}$ studied the biomechanical properties of the ascending thoracic aorta in 17 patients who underwent surgery for the resection of an ascending thoracic aortic aneurysm (ATAA; mean diameter of $56.16 \mathrm{~mm}$ ). The authors performed an in vivo intraoperative speckle-tracking transesophageal echocardiogram (STTEE) and calculated the aortic stiffness index. Furthermore, during the operation, a ring-shaped segment of the excised ascending thoracic aorta was sent to the laboratory for tissue stress-strain analysis and a green strain calculation index. Results of an in vivo examination by STTEE disclosed that the anterior aortic wall had the lowest stiffness index and was less significant than the inner curvature and posterior wall. For the ex vivo stiffness examination, there was a similar pattern of apparent stiffness as in the vivo samples, with the outer aortic wall curvature the stiffest. There was no significant linear correlation between the in vivo and ex vivo stiffness studies.

This work is an interesting and valuable publication, only limited by its relatively small sample size. The paper has the novel feature of investigating the stiffness index in the ascending thoracic aorta of patients with an ATAA in 2 ways: an in vivo intraoperative STTEE and an ex vivo examination in the laboratory. Despite the obtained results and the comparative study carried out, the main, more relevant message of the article is to point out the importance of the STTEE as a less-invasive diagnostic method in patients with ATAA.

In agreement with the authors, further research on this topic needs to be done. New different reliable metrics of aortic biomechanics should be investigated. The biomechanic characteristics and behavior of the aorta in patients with aortic aneurysms have been studied with high-resolution and advanced speckle-tracking echocardiography, ${ }^{2}$ 2dimensional and 3-dimensional ultrasound speckle-tracking examination, ${ }^{3,4}$ and thoracic and abdominal aortic highresolution computed tomography and magnetic resonance

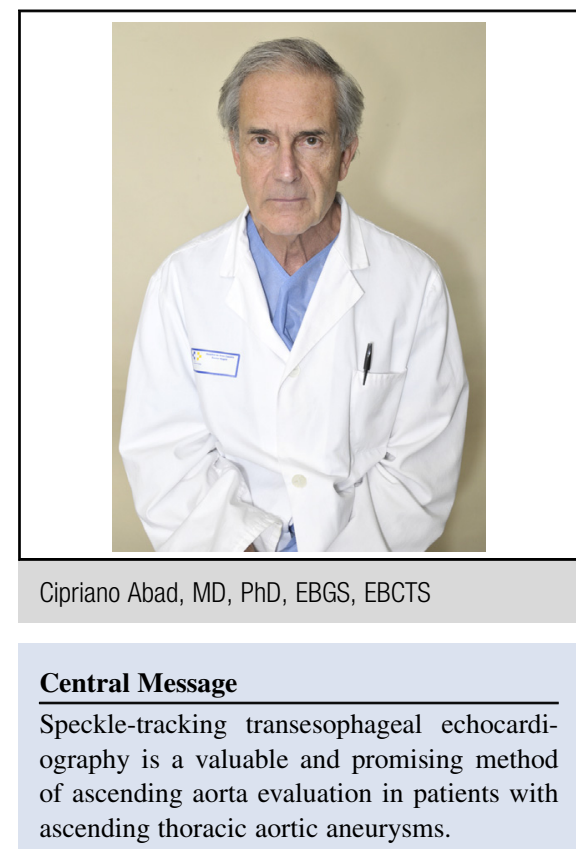

See Article page 781 .

imaging. ${ }^{5}$ A larger diameter of the thoracic aorta, aging, arterial hypertension, and other conditions lead to aortic tissue remodeling, aortic wall degeneration, loss of elastic fibers, and aortic stiffness. With the increased longevity achieved in Western populations and developed countries, a significant number of patients with sclerosis, stiffness, dilatation, or aneurysm in the aorta are expected to undergo cardiovascular medical assessment.

The study of the biomechanic characteristics of the ascending thoracic aorta by measurement of the stiffness index by STTEE can be a reliable method of evaluation, classification, and selection in patients with a dilated aorta or aneurysm. Furthermore, the stiffness index can be a predictor of ascending thoracic aorta enlargement-related complications such as aneurysm, dissection, or rupture.

Speckle-tracking echocardiography appears to be an accurate and innovative method to study the biomechanics of the ascending thoracic aorta in patients with ATAA. The work of Alreshidan and colleages ${ }^{1}$ represents an important contribution in this field.

In recent years, a significant increase in the number of ascending thoracic aorta operations has been registered in all cardiac centers. Surgery of the ascending thoracic aorta 
is becoming a frequent major surgical cardiovascular procedure. The ascending aorta, aortic root, and aortic valve represent a complex unit. Further studies on innovative, new, noninvasive methods of diagnostic and understanding the biomechanics of the ascending thoracic aorta should be encouraged.

\section{References}

1. Alreshidan M, Shahmansouri N, Chung J, Lash V, Emmott A, Leask RL, et al. Obtaining the biomechanical behavior of ascending aortic aneurysms by using novel speckle tracking echocardiography. J Thorac Cardiovasc Surg. 2017;153: $781-8$.
2. Texeira R, Moreira M, Baptista R, Barbosa A, Martins R, Castro G, et al. Circumferential ascending aortic strain and aortic stenosis. Eur Heart $J$ Cardiovasc Imaging. 2013;14:631-41.

3. Batagini NC, Ventura CA, Raghavan ML, Chammas MC, Tachibana A, Da Silva ES. Volumetry and biomechanical parameters detected by $3 \mathrm{D}$ and $2 \mathrm{D}$ ultrasound in patients with and without an abdominal aortic aneurysm. Vasc Med. 2016;21:209-16.

4. Karatolios K, Wittek A, New TH, Bihari P, Shelke A, Josef D, et al. Method for aortic wall strain measurement with three-dimensional ultrasound speckle tracking and fitted finite element analysis. Ann Thorac Surg. 2013;96: 1664-71.

5. Burk J, Blanke P, Stankovik Z, Barker A, Russe M, Geiger J, et al. Evaluation of 3D blood flow patterns and wall shear stress in the normal and dilated thoracic aorta using flow-sensitive 4D CMR. J Cardiovasc Magn Reson. 2012;14:84. 